\title{
Speciation of heavy metals in electroplating industry sludge and wastewater residue using inductively coupled plasma
}

\author{
P. Venkateswaran; S. Vellaichamy; ${ }^{*}$ K. Palanivelu \\ Centre for Environmental Studies, Anna University, Chennai 600 025, India \\ Received 10 February 2007; revised 10 April 2007; accepted 25 August 2007; available online 1 September 2007
}

\begin{abstract}
The speciation of metals in environmental samples is a critical factor in assessing the potential environmental impacts, before their disposal. The distribution and speciation of toxic heavy metals in plating wastewater residues and sludge was investigated for four samples using sequential extraction method. Tessier method was used to fractionate the metal content into exchangeable, acid extractable, reducible and oxidizable fractions. Residual and total metal contents were determined in aqua regia digest. The extracts were analysed for metals using inductively coupled plasma -atomic emission spectrometry. The bioavailable fraction (exchangeable and acid extractable fractions) is comprised less than the other forms. The oxidisable and reducible forms are dominants for all the four samples studied. The major metal constitute in the samples is iron, the wastewater residue contains (12.3 and 7.4 g/Kg respectively on dry basis) and the sludge contains ( 31.5 and $41.6 \mathrm{~g} / \mathrm{Kg}$ ) respectively. $\mathrm{Cr}$ concentration is higher in wastewater residue of second electroplating industry. The descending order of the average total metal contents for these four samples were $\mathrm{Fe}>\mathrm{Cr}>\mathrm{Sn}>\mathrm{Zn}>\mathrm{Cu}>\mathrm{Ni}>\mathrm{Mn}>\mathrm{Pb}>\mathrm{Cd}>\mathrm{Ag}$. Based on the average of absolute values for the four samples the highest bioavailability order of metals is $\mathrm{Cr}$ (39 \%) in wastewater residues and Zn (32 \%) in sludge samples. Metal recovery was good, with $<10 \%$ difference between the total metal recovered through the extractant steps and the total metal determined using aqua regia extract.
\end{abstract}

Key words: Wastewater residue, electroplating sludge, sequential extraction, metal speciation

\section{INTRODUCTION}

The occurrence of heavy metals in industrial wastewater is of interest because they are often present at significant levels and if discharged into surface waters can have severe effects on the environment and public health. The determination of total heavy metal content does not provide useful information about the risks of bioavailability, the capacity for remobilisation and the behavior of the metals in the environment (Luoma, 1989; Di Toro, et al., 1990; Sims and Sklin, 1991, Hsu and Lo, 2001). Metal speciation, in this context, is taken to mean the fractionation of the total metal content into exchangeable (bound to exchangeable sites of clay minerals), acid extractable (bound to carbonates and hydroxides), reducible (bound to Fe/Mn oxides), oxidisable (bound to organic matter/ sulfides) and residual (bound to clay minerals) forms. The chemical forms of the metal control its bioavailability or mobility (Norvell, 1984). The exchangeable and acid extractable fractions are mobile fractions that are easily bioavailable. Metals in oxic sediments are mainly distributed in different operationally defined geochemical phases, \*Corresponding Author Email: kpvelu@hotmail.com Tel.: +91 442220 3195; Fax: +91 4422354717 such as carbonates, total organic carbon (TOC), and Fe - Mn oxides, which have diverse binding abilities with various metals and have contrasting influences on the metal bioavailability (Tessier and Camp bell, 1987; Bryan and Langston, 1992; Coquery and Wekboum, 1999). For anoxic sediments, the acid-volatile sulfide (AVS, or the sulfides removed from sediment by cold acid extraction) is considered as an important factor in affecting the bioavailability of most divalent metals having a high affinity with sulfide (Di Toro, et al., 1990; Ankley, et al., 1996; USEPA, 2001). It is necessary to know the physical and chemical properties of any solid waste before their disposal, and particularly their elemental contents, both in terms of total concentrations and the amount that is potentially biologically effective. However, the determination of specific chemical species or binding forms is difficult and often virtually impossible. For this reason, sequential extraction procedures are commonly applied because they provide information about the fractionation of metals in the different lattices of the solid sample, which is a good compromise method that gives information on the environmental contamination 
risk. (Campos, et al., 1998, Scancar, et al., 2000, Pueyo, et al., 2001). Method developed by Tessier, et al., (1979) is the one widely used for this purpose. Kazi, et al., (2005) evaluates the mobility of toxic metals in untreated industrial wastewater sludge. The results from the partitioning study indicate that more easily mobilized forms (acid exchangeable) of Cd were dominant. The oxidizable fraction was dominant for all four toxic metals ( $\mathrm{Cr}, \mathrm{Pb}, \mathrm{Ni}, \mathrm{Cd}$ ). It was observed that levels of leachable toxic metals from industrial wastewater sludge were low compared to the amount of metal extracted in the exchangeable fraction of the BCR protocol. Karbassi and Shankar, (2005) reported that in the coastal sediment cores $\mathrm{Cu}, \mathrm{Zn}$ and $\mathrm{Fe}$ are associated with organic matter and detrital particles, whereas $\mathrm{Ni}$ and $\mathrm{Co}$ are predominantly associated with the insoluble fraction. While abundance of calcareous shells in some zones has lead to the dilution of most of the metals, it appears that $\mathrm{Pb}$ and $\mathrm{Mn}$ are associated with this phase. Later, Karbassi, et al. (2006) reported that higher elemental concentrations have been observed in estuarine zone when compared with riverine sediments (except for $\mathrm{Al}, \mathrm{Fe}, \mathrm{Pb}$ and $\mathrm{Mn}$ ). Saeedi, et al., (2004) reported the potential of reverine suspended particulate matter and bottom sediments in adsorbing dissolved metals like $\mathrm{Cd}, \mathrm{Mn}$. Ni, Cu, Zn. The presence of metals in sea sediments and increase in their concentration may be indicative of human influence on aquatic environment like agricultural, industrial activities. The sequential extraction scheme as per the Standard, Measurements and Testing Programme of the European Commission was studied by Alonso, et al., (2005) for the sludge samples from anaerobic wastewater stabilization ponds. Elements namely Al, Cd, Co, Cr, Cu, Fe, Hg, Mn, Mo, Ni, Pb, Ti and $\mathrm{Zn}$ were determined in the sludge extracts by ICPAES. In relation to current international legislation for the use of sludge for agricultural purposes, none of the metal concentrations exceeded maximum permitted levels. Overall, heavy metals were mainly associated with the two less-available fractions (34\% oxidizable metal and $55 \%$ residual metal). Only Mn and Zn showed the highest share of the available (exchangeable and reducible) fractions (25 - $48 \%$ ). In this present paper, wastewater residue and sludge samples collected from two plating industries located in Chennai, India was examined for distribution of heavy metals like Ag, Cd, Cr, Cu, Fe, Mn, Ni, Pb, Sn, and Zn, using ICP - AES and chemical fractions of these heavy metals by sequential extraction to assess their potential environmental impacts.

\section{MATERIALS AND METHODS}

Sludge and wastewater samples were collected from the effluent treatment plants of two different electroplating industries located in Chennai, India. The wastewaters were filtered and residues were taken for the study and before analysis; samples were dried at $105{ }^{\circ} \mathrm{C}$ to remove moisture and grinded in an agate mortar to reduce particle size and stored in polyethylene containers. The extraction was carried with an initial mass of $1.0 \mathrm{~g}$ oven dried sample. The selective extraction was carried out in polypropylene centrifuge tubes of $50 \mathrm{~mL}$ capacity. After each successive extraction, the supernatant liquid was removed after centrifugation at $2500 \mathrm{rpm}$ for $5 \mathrm{~min}$ and diluted to volume. The residue was washed with $10 \mathrm{ml}$ of distilled water by shaking and centrifugation without loss of solids. The extracts were stored in polythene bottles for metal content determination. The conventional method developed by Tessier, et al., (1979) was followed for the sequential extraction. The residual and total metal contents were determined in aqua regia digest (Esakku, et al., 2005; Shrivastava and Banerjee, 1998). The residual fractions of the sequential extracted samples and the total metal content in fresh samples were extracted with aqua regia using a behrotest digester block with a TRS 200 microprocessor controller.

(1) Exchangeable: About $1.0 \mathrm{~g}$ sample was extracted at room temperature with $8 \mathrm{~mL}$ of $1 \mathrm{M} \mathrm{MgCl}_{2}(\mathrm{pH} 7)$ with continuous agitation for $1 \mathrm{~h}$.

(2) Acid extractable: Residue from above step (1) was leached at room temperature with $8 \mathrm{~mL}$ of $1 \mathrm{M}$ of $\mathrm{NaOAc}$ (pH 5 adjusted with $\mathrm{HOAc}$ ) with continuous agitation for $5 \mathrm{~h}$.

(3) Reducible: Residue from (2) was extracted with 20 $\mathrm{mL}$ of $0.04 \mathrm{M} \mathrm{NH}_{2} \mathrm{OH} . \mathrm{HCl}$ in $25 \%$ (v/v) HOAc agitated for $6 \mathrm{~h}$ at $96^{\circ} \mathrm{C}$.

(4) Oxidizable: To the residue from (3) were added $3 \mathrm{~mL}$ of $0.02 \mathrm{M} \mathrm{HNO}_{3}$ and $5 \mathrm{~mL}$ of $30 \% \mathrm{H}_{2} \mathrm{O}_{2}$ (pH 2, adjusted with $\mathrm{HNO}_{3}$ ); heated at $85{ }^{\circ} \mathrm{C}$ for $2 \mathrm{~h}$ with occasional agitation. A second $3 \mathrm{ml}$ aliquot of $30 \% \mathrm{H}_{2} \mathrm{O}_{2}$ was added and heated at $85{ }^{\circ} \mathrm{C}$ for $3 \mathrm{~h}$ with occasional agitation. After cooling, $5 \mathrm{~mL}$ of $3.2 \mathrm{M} \mathrm{NH}_{4} \mathrm{OAc}$ in $20 \%(\mathrm{v} / \mathrm{v})$ $\mathrm{HNO}_{3}$ was added; diluted to $20 \mathrm{~mL}$; agitated for $30 \mathrm{~min}$ and centrifuged.

(5) Residual: Residue from (4) was digested with $8 \mathrm{~mL}$ of aqua regia $\left(\mathrm{HCl}\right.$ and $\mathrm{HNO}_{3}, 3+1 \mathrm{v} / \mathrm{v}$ ) for $2 \mathrm{~h}$ at $120^{\circ} \mathrm{C}$. 
(6) Total: Fresh sample, $1.0 \mathrm{~g}$, was digested with $8 \mathrm{~mL}$ of aqua regia $\left(\mathrm{HCl}\right.$ and $\left.\mathrm{HNO}_{3}, 3+1 \mathrm{v} / \mathrm{v}\right)$ for $2 \mathrm{~h}$ at $120^{\circ} \mathrm{C}$. An inductively coupled plasma -atomic emission spectrometry (ICP-AES), Thermo (IRIS intrepid II, XSP) with thermo elemental variation analyzer (TEVA) operating software was used for the determination of elements namely Ag, Cd, Cr, Cu, Ni, Pb, Sn, Mn, Fe and $\mathrm{Zn}$. While analyzing samples, two or more lines for each element were selected to provide confirmation of the analytical results. Double distilled water was used for the preparation of reagents. Reagent blanks were prepared with the same amounts of reagents used in the analytical procedures. Two replicated samples were used for the extraction study and the average results of triplicate analysis were reported. The reference standard (Thermo) was also analyzed simultaneously for quality control.

\section{RESULTS}

Total content of heavy metals in samples

The total contents of elements namely Ag, $\mathrm{Cd}, \mathrm{Cr}, \mathrm{Pb}$, $\mathrm{Cu}, \mathrm{Ni}, \mathrm{Sn}, \mathrm{Mn}, \mathrm{Fe}$ and $\mathrm{Zn}$ for the samples collected from two different electroplating industries (EPI) at Chennai, India are presented in Table 1 . The results presented in Table 1 shows a wide variation in the concentration of heavy metals. In general, these samples had higher concentration of $\mathrm{Cr}, \mathrm{Cu}, \mathrm{Fe}, \mathrm{Sn}$ and $\mathrm{Zn}$ but relatively lower concentration of $\mathrm{Mn}, \mathrm{Ni}, \mathrm{Pb}$ and traces of $\mathrm{Ag}$ and $\mathrm{Cd}$ were found. This difference in concentration of metals may due to the nature of plating required and the composition used in the plating bath.

\section{Fractionation of heavy metals}

Sediments are generally the sinks for metals in aquatic environment and constitute an enriched metal pool that can be potentially accumulated by the benthic animals (Campbell, et al., 1988). In the sequential extraction scheme used in this study, the mobility and hence possible bioavailability of metals are lower.

The higher concentrations of reducible and oxidisable fractions were found in $\mathrm{Cr}, \mathrm{Cu}, \mathrm{Ni}, \mathrm{Mn}, \mathrm{Pb}$, $\mathrm{Zn}$ and traces of $\mathrm{Ag}$ and $\mathrm{Cd}$ were found in these fractions. The per cent contributions of exchangeable, acid extractable, reducible, oxidisable and residual species in total metal concentration obtained after fractionation of the 4 samples studied $(n=3)$ for $\mathrm{Ag}$, $\mathrm{Cd}, \mathrm{Cr}, \mathrm{Pb}, \mathrm{Cu}, \mathrm{Ni}, \mathrm{Sn}, \mathrm{Mn}, \mathrm{Fe}$ and $\mathrm{Zn}$. The four samples collected from plating industries are coded accordingly where, $1=$ wastewater residue of EPI -1; 2 = ETP sludge of EPI -1; 3 = wastewater residue of EPI -2 and $4=$ ETP sludge of EPI -2. The results are depicted in Fig. 1.

\section{Mobile fractions}

The mobile fractions of trace metals are more available for environmental functions than other fractions. In the ecological context, the mobile fractions rather than the total metal content are important. Further the chemical species play important role in transfer of metals along the water soil plant animal human chain (Shrivastava and Banerjee, 1998). Comparison of the percentage of mobile fraction (sum of exchangeable and acid extractable fractions) to the total metal content is furnished in Table 2.

Table 1: Total elemental content in plating industry samples

\begin{tabular}{|c|c|c|c|c|c|}
\hline \multirow{2}{*}{ No. } & \multirow{2}{*}{ Element } & \multicolumn{4}{|c|}{ Sample code } \\
\hline & & 1 & 2 & 3 & 4 \\
\hline 1 & $\mathrm{Ag}$ & 15.9 & 3.3 & 13.3 & 1.3 \\
\hline 2 & $\mathrm{Cd}$ & 16.6 & 3.3 & 9.3 & 3.3 \\
\hline 3 & $\mathrm{Cr}$ & 10998 & 3226 & 13498 & 3566 \\
\hline 4 & $\mathrm{Cu}$ & 598 & 4632 & 693 & 5996 \\
\hline 5 & $\mathrm{Fe}$ & 12332 & 31530 & 7499 & 41629 \\
\hline 6 & Mn & 326 & 303 & 336 & 303 \\
\hline 7 & $\mathrm{Ni}$ & 409 & 950 & 456 & 966 \\
\hline 8 & $\mathrm{~Pb}$ & 27.6 & 53.3 & 27.9 & 766 \\
\hline 9 & Sn & 8332 & 7632 & 7899 & 7499 \\
\hline 10 & $\mathrm{Zn}$ & 8799 & 2733 & 2519 & 6865 \\
\hline
\end{tabular}

Conditions: All the values are expressed in $\mathrm{mg} / \mathrm{Kg}$ of sample - dry weight. Sample code, (1) Wastewater residue of EPI- 1, (2) ETP sludge of EPI- 1, (3) Wastewater residue of EPI- 2 and (4) ETP sludge of EPI -2. 


\section{DISCUSSION AND CONCLUSION}

Though iron is not a toxic heavy metal, it was also analysed in the present study as it is used in ETP for precipitation and the results discussed since it is the predominant metal available in all the four samples. Less than $20 \%$ of $\mathrm{Fe}$ is available in acid extractable form in the wastewater residues of both the samples, and traces of metal available in exchangeable form. More than $50 \%$ samples followed by oxidisable and residual fractions.
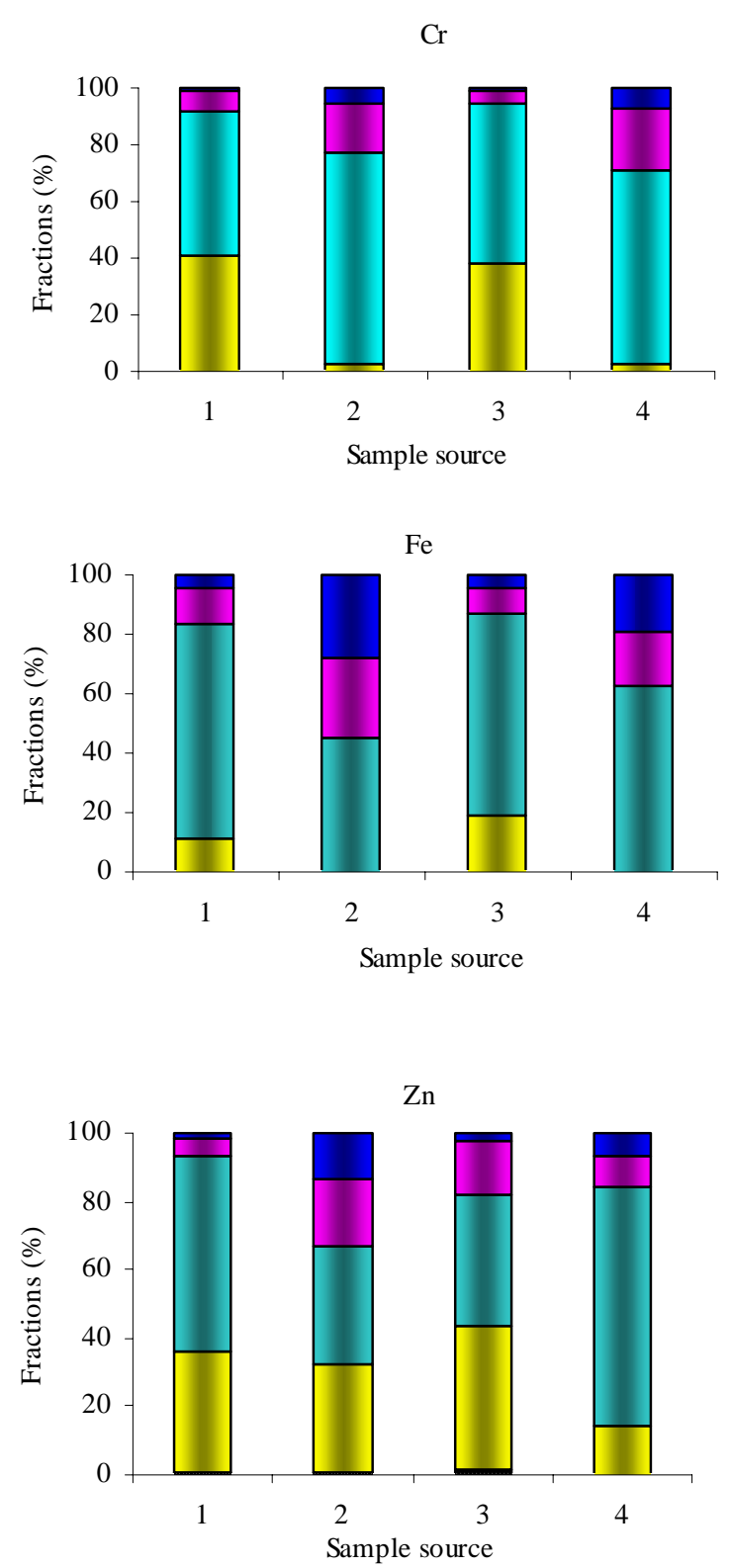

Less than $5 \%$ of residual fractions were observed in wastewater residues and $27 \%$ and $19 \%$ were observed for the sludge samples 2 and 4 respectively. If the concentration of metal is too high, the efficiency of the fraction may be reduced, as reported for lead (Staelens, et al., 2000; Rauret, et al., 1989). Since the Fe concentration is very high the sequential extraction may be less effective with other fractionations. Otte, et al., (1995) reported that the residual fraction could be converted to reducible fraction by the activity of plant roots.
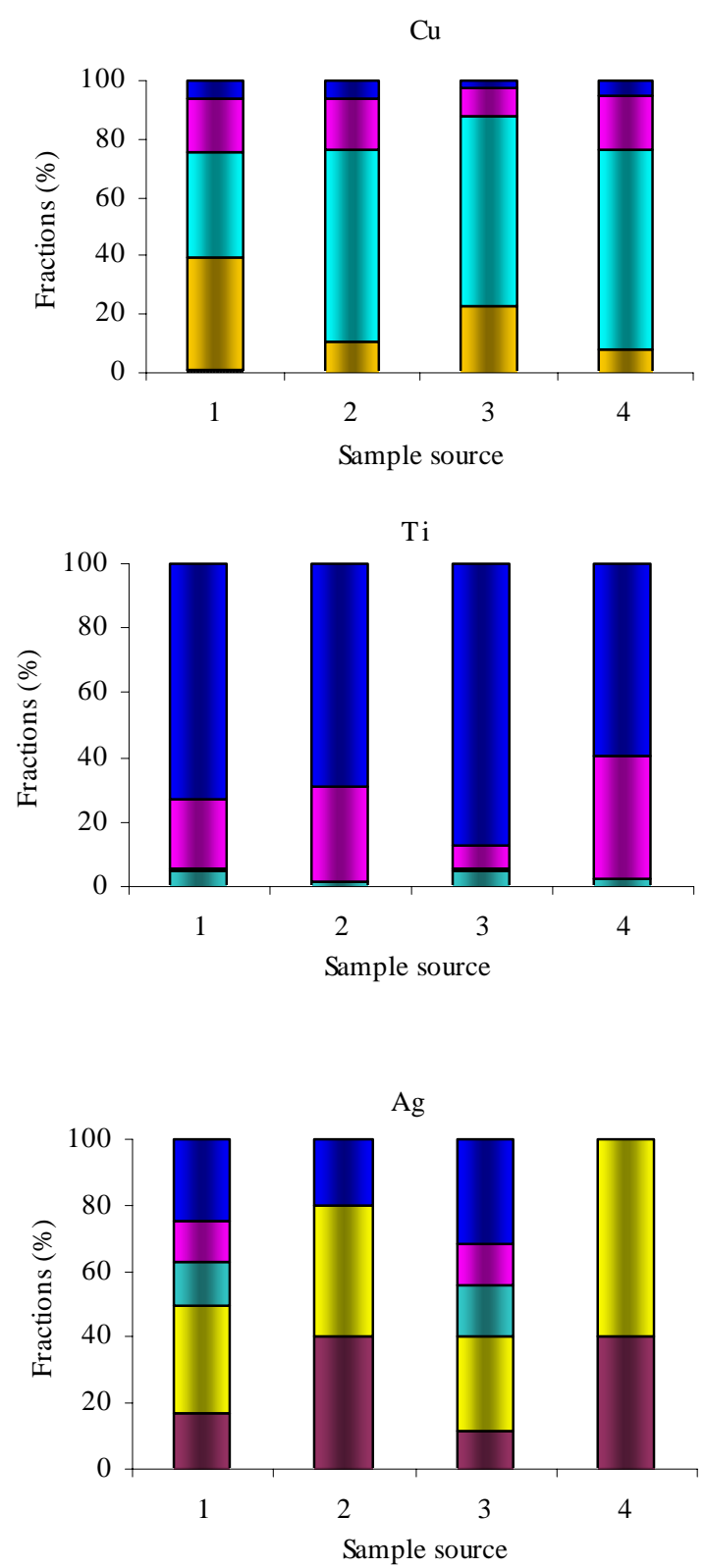
$\mathrm{Pb}$

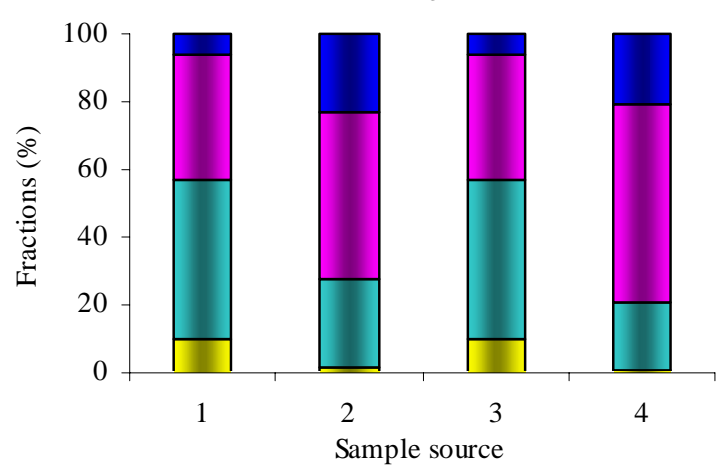

$\mathrm{Ni}$

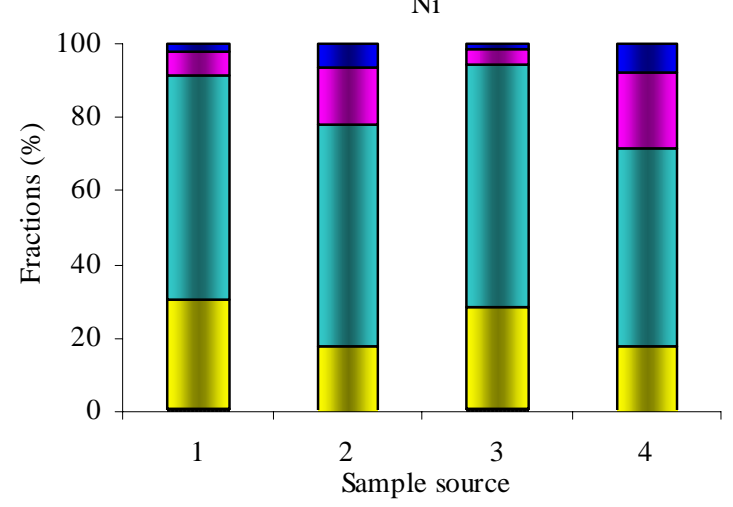

Cd
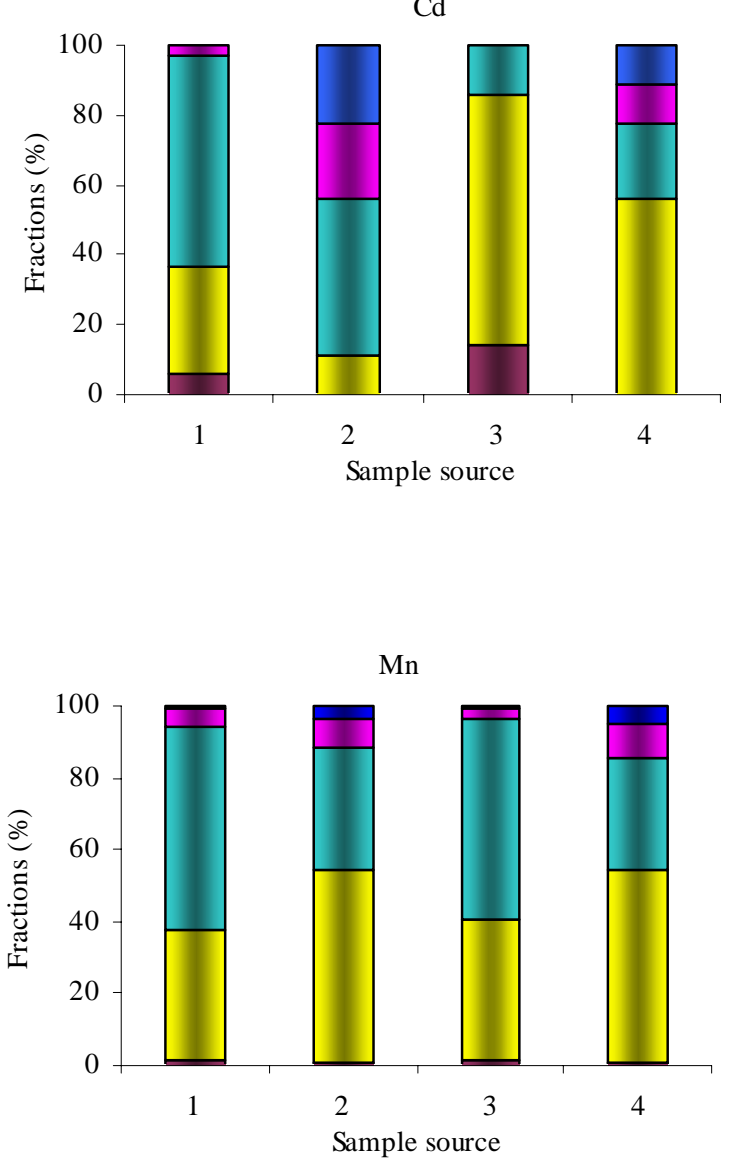

$\square$ Exchangeable $\square$ Acid extractable

$\square$ Reducible $\square$ Oxidizable

Residual

Fig. 1: Percentage of various species of metals in fine fractions of plating wastewater residue and sludge samples

Table 2: Percent mobile fractions of elements in fine fractions

\begin{tabular}{|c|c|c|c|c|c|}
\hline \multirow{2}{*}{ No. } & \multirow{2}{*}{ Element } & \multicolumn{4}{|c|}{ Sample code } \\
\hline & & 1 & 2 & 3 & 4 \\
\hline 2 & $\mathrm{Cd}$ & 36.3 & 11.2 & 85.7 & 55.6 \\
\hline 4 & $\mathrm{Cu}$ & 39.5 & 10.4 & 22.5 & 7.7 \\
\hline 5 & $\mathrm{Fe}$ & 11.6 & 0.9 & 18.7 & 0.4 \\
\hline 6 & $\mathrm{Mn}$ & 37.7 & 54.3 & 40.4 & 54.4 \\
\hline 9 & $\mathrm{Sn}$ & 4.6 & 0.7 & 5.1 & 0.4 \\
\hline 10 & $\mathrm{Zn}$ & 35.8 & 32.3 & 43.2 & 14.1 \\
\hline
\end{tabular}

Conditions: Sample code, (1) Wastewater residue of EPI- 1, (2) ETP sludge of EPI- 1, (3) Wastewater residue of EPI- 2 and (4) ETP sludge of EPI -2. Mobile fraction is the sum of exchangeable and acid extractable fractions. Percentage based on total content obtained by adding fractions. 
P. Venkateswaran, et al.

Table 3: Per cent recovery of metals in sequential extraction with respect to aqua regia extract

\begin{tabular}{|c|c|c|c|c|c|}
\hline \multirow{2}{*}{ No. } & \multirow{2}{*}{ Element } & \multicolumn{4}{|c|}{ Sample code } \\
\hline & & 1 & 2 & 3 & 4 \\
\hline 1 & $\mathrm{Ag}$ & 104 & 104 & 92 & 93 \\
\hline 2 & $\mathrm{Cd}$ & 95 & 108 & 94 & 97 \\
\hline 3 & $\mathrm{Cr}$ & 108 & 107 & 106 & 116 \\
\hline 4 & $\mathrm{Cu}$ & 109 & 104 & 94 & 97 \\
\hline 5 & $\mathrm{Fe}$ & 98 & 90 & 94 & 99 \\
\hline 6 & Mn & 105 & 105 & 106 & 91 \\
\hline 7 & $\mathrm{Ni}$ & 104 & 107 & 105 & 98 \\
\hline 8 & $\mathrm{~Pb}$ & 90 & 94 & 107 & 110 \\
\hline 9 & Sn & 109 & 109 & 90 & 92 \\
\hline 10 & $\mathrm{Zn}$ & 95 & 109 & 98 & 108 \\
\hline
\end{tabular}

Conditions: Sample code, (1) Wastewater residue of EPI- 1, (2) ETP sludge of EPI- 1, (3) Wastewater residue of EPI- 2 and (4) ETP sludge of EPI -2.

The percent recovery of metals obtained by the summation of sequential fractions in relation to the total metal content extracted with aqua regia is presented in Table 3. The recovery rate of sequential extracted metal concentration to total metal concentration was mostly between $90 \%$ and $110 \%$, therefore all analyses were considered satisfactory. This variation may be attributed to the differences in leaching time, reagents and the total volume of extractant (Ciba, et al., 1999). In the wastewater residues $40 \%$ of the metal is presented in acid extractable form, where as in the sludge samples only $2 \%$ are available. Around $70 \%$ of the metal is available in reducible fractions for the sludge samples and 50, $56 \%$ are present in wastewater residues respectively. There are no exchangeable fractions of Cr noticed in all the samples, the leaching of $\mathrm{Cr}$ to environment from these samples may not occur readily. The increasing order of fraction of chromium in wastewater residue is exchangeable $<$ residual $<$ oxidisable $<$ acid extractable $<$ reducible, whereas in sludge samples exchangeable $<$ residual $<$ acid extractable $<$ oxidisable $<$ reducible. Chromium (VI) is a highly toxic metal that has been linked to cancer in humans following prolonged inhalation, and is toxic to aquatic life at relatively low concentrations (US Environmental Protection Agency (EPA), 1998).

The predominant form of copper available in the entire fractions is reducible fractions, followed by oxidisable, acid extractable, residual and exchangeable. The mobile fraction of copper contributes up to $40 \%$ in wastewater residues and less than $10 \%$ in sludge samples. The highest fraction of copper species is reducible followed by oxidisable fractions. The higher stability constant of copper complexes with organic matter leads to higher organic fractions. Only under strong oxidizing conditions $\mathrm{Cu}$ can be leached into the environment. The residual fractions of copper are less than $7 \%$ only and the least fraction is exchangeable.
Tin is one of the major content from the plating effluent. The highest fraction obtained for tin is the residual fraction. The percentage of residual fractions is 72,68 , 87 and 59 respectively for the four electroplating industry samples. Based on the metal concentration, order of sequential fraction is residual $>$ oxidisable $>$ acid extractable $>$ reducible $>$ exchangeable. There is no exchangeable fractions of tin is found. Among all the metals determined, $\mathrm{Sn}$ is the one that contributes the highest to the residual or inert phase, which are not easily bioavailable (Norvell, 1984).

The predominant form of $\mathrm{Zn}$ is the reducible fraction, followed by acid extractable, oxidisable, residual and exchangeable. There is no significant variation in absolute mobile fractions (exchangeable and acid extractable) in the three samples of about 35.8, 32.6, 43.2 percent respectively and $16 \%$ in the fourth sample. The residual fractions are higher in the sludge samples than the wastewater residues. Perez-Cid, et al., (1996) reported similar levels of $\mathrm{Zn}$ in reducible form in sewage sludge. Higher concentration of heavy metals in reducible fraction (bound to Fe and Mn oxides) can be attributed to diffusion mechanism (Backes, et al., 1995). These metals can be released into the environment under extremely reducible conditions. The order of availability of $\mathrm{Pb}$ in different fractions in wastewater residues is reducible $>$ oxidisable $>$ acid extractable $>$ residual $>$ exchangeable. Where as in the sludge samples oxidisable $>$ residual $>$ reducible $>$ acid extractable $>$ exchangeable. The higher contribution of lead at reducible form than other fractions like residual, acid extractable, exchangeable fractions are due to the precipitation of lead as stable compounds. Kinniburgh, et al., (1976) observed the excess lead content in the reducible fraction at low $\mathrm{pH}$. About $10 \%$ of $\mathrm{Pb}$ contributes to mobile form (exchangeable and acid extractable fractions) in wastewater residues, where as $1.5 \%$ were available in sludge samples. 
Reducible fraction is the predominant form on $\mathrm{Ni}$ in all the samples. The percent of reducible fractions are 60, 63, 65 and 53 respectively representing hydrous oxides of Fe and $\mathrm{Mn}$. The decreasing order of fractions in the samples are reducible $>$ acid extractable $>$ oxidisable $>$ residual $>$ exchangeable. About $15-30 \%$ is in exchangeable and acid extractable forms which can cause environmental toxicity during mobility (Karbassi and Shankar, 2005). The acid extractable fraction is soluble in the low $\mathrm{pH}$ condition. Negligible amount of exchangeable fractions of manganese is found in all the samples. Acid extractable and reducible forms occupy the highest proportions. The reducible form is higher (50\%) in wastewater residues and acid extractable form is higher (50\%) in the sludge samples that are easily bioavailable (Tessier and Campbell, 1987). There are no residual fractions in wastewater residues and around $1.5 \%$ found in the sludge samples. Cd is the least abundant metal in the plating wastes, when comparing with other available metals. The exchangeable fraction of Cd is $6-14 \%$ in wastewater residue samples and traces in sludge samples, similar to the observation by Kazi, et al., (2005) in wastewater sludge. About 50 $\%$ of acid extractable fractions constitute the samples 3 and 4 where as 32 and $10 \%$ in samples 1 and 2 respectively. The residual fractions are found 25 and $16 \%$ respectively in the sludge samples. The appropriate disposition of cadmium sludge constitutes serious environmental problems. Ag is a precious metal of technological and environmental importance. The concentrations of silver in the plating samples are very low. The exchangeable fractions which are easily available (Coquery and Wekboum, 1999) constitute about $40 \%$ in the sludge samples and less than $20 \%$ in the wastewater residues. Based on the metal concentration, order of sequential fraction in sludge sample is exchangeable $>$ acid extractable $>$ residual oxidisable $>$ oxidisable $>$ reducible. The exchangeable fraction corresponds to the metal species that are most easily available for plant uptake, which can be released by merely changing the ionic strength of the medium (Norvell, 1984). The metal content bound to carbonates is sensitive to $\mathrm{pH}$ changes and this can become mobilized when the $\mathrm{pH}$ is lowered. The metal fraction bound to Fe - Mn oxides and organic matter can be mobilized when environmental conditions become increasingly reducing or oxidizing (Bryan and Langston, 1992). The mobile fraction studies reveals that metals like tin, lead, iron possess the least and elements like silver, cadmium possess the highest percentage of mobile fractions in the range 35-99 \% calculated based on the total content obtained by adding fractions. The metal fraction associated with the residual fraction (such as silicate) can only be mobilized as a result of weathering, so this is only associated with long-term effects. Among all the ten metals analyzed, Fe is the highest and the Ag is the lowest in absolute concentrations for the samples analysed. The heavy metals studied contribute significant quantities in exchangeable and acid extractable fractions, which are easily bioavailable. These metals can be leached during the changes in environmental conditions and poses threat to groundwater quality. In the case of Sn, the residual fraction contributes the maximum, which is inert form and hence the environmental effects may not be significant. The mobile fractions of $\mathrm{Pb}$ are less and appreciable amounts of $\mathrm{Pb}$ existed in oxidizable form, which can be leached only under extreme oxidizing conditions. Since the contribution of heavy metals in mobile fractions is in the range up to $99 \%$, the waste material should be dumped in landfills after stabilization to prevent the leaching of metals.

\section{ACKNOWLEDGEMENTS}

The authors would like to thank the University Grants Commission (UGC) for their support under the Centre with Potential for Excellence in Environmental Science (CPEES) scheme. P.Venkateswaran and S.Vellaichamy is grateful to Council of Scientific and Industrial Research (CSIR), India for providing financial assistance under SRF scheme.

\section{REFERENCES}

Alonso, E.; Villar, P.; Santos, A.; Aparicio, I., (2006). Fractionation of heavy metals in sludge from anaerobic wastewater stabilization ponds in southern Spain., Waste Manage., 26 (11), 1270-1276.

Ankley, G.T.; Di Toro, D.M.; Hansen, D.J.; Berry, W.J.; (1996). Technical basis and proposal for deriving sediment quality criteria for metals. Environ. Toxicol. Chem., 15, 2060-2066.

Backes, C.A.; McLaren, R.G.; Rate, A.W.; Swift, R.S., (1995). Kinetics of cadmium and cobalt desorption from iron and manganese oxides. Soil Sci. Soc. Am. J., 59, 778-785.

Bryan, G.W.; Langston, W.J., (1992). Bioavailability, accumulation and effects of heavy metals in sediments with special reference to United Kingdom estuaries: Rev. Environ. Pollut., 76, 89-131.

Campbell, P.G.C.; Lewis, A.G.; Chapman, P.M.; Crowder, A.A., Fletcher, W.K., Imber, B.; Luoma, S.N.; Stokes, P.M.; Winfrey, M., (1988). Biologically available metals in sediments. National Research Council of Canada, Ottawa, Canada, Publ. 27694. 
Campos, E.; Barahona, E.; Lachica, M.; Mingorance, M.D., (1998). A study of the analytical parameters important for the sequential extraction procedure using microwave heating for $\mathrm{Pb}, \mathrm{Zn}$ and $\mathrm{Cu}$ in calcareous soils. Anal. Chem. Ac., 369, 235-243.

Ciba, J.; Korolewicz, T.; Turek, M., (1999). The occurrence of metals in composted municipal wastes and their removal. Water Air Soil Pollut., 111, 159-170.

Coquery, M.; Wekbourn, P.M., (1999). The relationship between metal concentration and organic matter in sediments and metal concentration in the aquatic macrophyte Eriocaulon septangulare. Water Res., 29, 2094-2102.

Di Toro, D.M.; Mahony, J.D.; Hansen, D.J.; Scott, K.J.; Hicks, M.B.; Mayr, S.M.; Redmond, M.S., (1990). Toxicity of cadmium in sediments: the role of acid volatile sulfide. Environ. Toxicol. Chem., 9, 1487-1502.

Esakku, S.; Selvam, A.; Kurian J.; Palanivelu, K.; (2005). Assessment of heavy metal species in decomposed municipal solid waste. Chem. Spec. Bioavailab., 17 (3), 95-102.

Hsu, J.H.; Lo, S.L., (2001). Effect of composting on characterization and leaching of copper, manganese, and zinc from swine manure. Environ. Pollut. 114, 119-127.

Karbassi, A.R.; Bayati, I.; Moattar, F., (2006) Origin and chemical partitioning of heavy metals in riverbed sediments. Int. J. Environ. Sci. Tech., 3, 35-42.

Karbassi, A.R.; Shankar, R., (2005). Geochemistry of two sediment cores from the west coast of India. Intl. J. Environ. Sci. Tech., 1, 307-316.

Kazi, T.G.; Jamali, M.K.; Kazi, G.H., Arain, M.B., Afridi, H.I. Siddiqui, A., (2005). Evaluating the mobility of toxic metals in untreated industrial wastewater sludge using a BCR sequential extraction procedure and a leaching test. Anal. Bioanal. Chem., 383, 297-304.

Kinniburgh, D.G.; Jackson, M.L.; Syers, J.K.; (1976). Adsorption of alkaline earth, transition and heavy metal cations by hydrous oxide gels of iron and aluminium. Soil Sci. Soc. Am. J., 40, 796-799.

Luoma, S.N., (1989). Can we determine the biological availability of sediment-bound trace elements? Hydrobiologia, 176-177, 379-396.

Norvell, W.A., (1984). Comparison of chelating agents for metals in diverse soil materials. Soil Sci. Soc. Am. J., 48, 1285-1292.
Otte, M.L.; Kearns, C.C.; Doyle, M.O., (1995). Accumulation of arsenic and zinc in the rhizosphere of wetland plants. Bull. Environ. Contam. Toxicol., 55, 154-161.

Perez-Cid, B.; Lavilla, I.; Bendicho, C., (1996). Analytical assessment of two sequential extraction schemes for metal partitioning in sewage sludges. Analyst, 121, 1479-1484.

Pueyo, M.; Rauret, G.; Lück, D.; Yli-Halla, M.; Muntau, H.; Quevauviller, Ph.; Lopez-Sanchez, J.F.,(2001).Certification of the extractable contents of $\mathrm{Cd}, \mathrm{Cr}, \mathrm{Cu}, \mathrm{Ni}, \mathrm{Pb}$ and $\mathrm{Zn}$ in a freshwater sediment following a collaboratively tested and optimised three-step sequential extraction procedure. J. Environ. Monitor. 3, 243-250.

Rauret, G.; Rubio, R.; Lopez-Sanchez, J.F.; Casassas, E., (1989). Specific procedure for metal solid speciation in heavily polluted river sediments. Int. J. Environ. Anal. Chem., 35, 89-100.Saeedi, M.; Daneshvar, Sh.; Karbassi, A.R., (2004). Role of riverine sediment and particulate matter in adsorption of heavy metals. Int. J. Environ. Sci. Tech. 1(2), 135-140.

Scancar J, Milacic R, Strazar M, Burica O (2000) Total metal concentrations and partitioning of $\mathrm{Cd}, \mathrm{Cr}, \mathrm{Cu}, \mathrm{Fe}, \mathrm{Ni}$ and Zn in sewage sludge. Sci. Total Environ., 250 (1-3), 9-19.

Shrivastava, S.K. and Banerjee, D.K., (1998). Operationally determined speciation of copper and zinc in sewage sludge. Chem. Speciat. Bioavail., 10, 137 -143.

Sims, J.T.; Sklin, J., (1991). Chemical fractionation and plant uptake of heavy metals in soils amended with co-composted sewage sludge. J. Environ. Qual., 20, 387-395.

Staelens, N.; Parkpian, P.; Polprasert, C., (2000). Assessment of metal speciation evolution in sewage sludge dewatered in vertical flow reed beds using a sequential extraction scheme. Chem. Speciat. Bioavail., 12, 97-107.

Tessier, A.; Campbell, P.G.C.; Bisson, M., (1979). Sequential extraction procedure for the speciation of particulate trace metals. Anal. Chem., 51, 844-851.

Tessier, A.; Campbell, P.G.C., (1987). Partitioning of trace metals in sediments: relationship with bioavailability. Hydrobiologia, 149, 43-52.

USEPA, (1998). Toxicological review of hexavalent chromium. Environmental Protection Agency.

USEPA, (2001). Methods for Collection, Storage and Manipulation of Sediments for Chemical and Toxicological Analyses: Technical Manual (EPA-823-B-01-002).

\section{AUTHOR (S) BIOSKETCHES}

Venkateswaran, P., M.Sc., is a research scholar (Ph.D) at Centre for Environmental Studies, Anna University, Chennai, India. E mail: meetvenke@yahoo.co.in

Vellaichamy, S., M.Sc., M.Phil., is a research scholar (Ph.D) at Centre for Environmental Studies, Anna University, Chennai, India. E mail: justinveda@yahoo.co.in

Palanivelu, K., Ph.D., is an assistant professor at Centre for Environmental Studies, Anna University, Chennai, India. E mail: kpvelu@hotmail.com

This article should be referenced as follows:

Venkateswaran, P.; Vellaichamy, S.; Palanivelu, K., (2007). Speciation of heavy metals in electroplating industry sludge and wastewater residue using inductively coupled plasma. Int. J. Environ. Sci. Tech., 4 (4), 497-504. 